\title{
Assessment of Diverse Frenal Morphology in Primary, Mixed, and Permanent Dentition: A Prevalence Study
}

\author{
Sharashchandra M Biradar ${ }^{1}$, Ambika Y Patil $^{2}$, Santosh S Kotnoor ${ }^{3}$, Shraddanand Bacha ${ }^{4}$, Shobha C Bijjaragi ${ }^{5}$, \\ Puttaraj Tukaram Kattimani ${ }^{6}$
}

\begin{abstract}
Aim: The maxillary labial frenum is a normal anatomic structure with inherent morphological variations. It has various morphologies and types depending on the attachment of fibers. This study was conducted to access the frenal morphology and frenal attachment in primary, mixed, and permanent dentition.

Materials and methods: This study includes 1,800 patients, in which 969 were males and 831 females, with 3-17 years of age and is equally divided into primary, mixed, and permanent according to age and dentition of patients. Morphology of maxillary labial frenum was examined and classified according to Sewerin's frenum typology and type of frenal attachment according to Placek's attachment. Data collected were entered into SPSS version 16 and were subjected to statistical analysis.

Results: Simple frenum is most prevalent in all the age groups followed by persistent tectolabial frenum (PTF) in primary dentition, frenum with a nodule in mixed dentition, and frenum with an appendix in permanent dentition. Type III frenal attachment is found in primary dentition followed by type II and type I in mixed and permanent dentition, respectively. There is a highly statistically significant difference in the type of frenal morphology and frenal attachment in all groups of dentition.

Conclusion: The prevalence of simple frenum is increasing from primary dentition to permanent dentition, whereas PTF decreases as age increases. This study reveals a high prevalence of gingival attachment followed by papillary attachment.

Clinical significance: The examination of frenal morphology and attachment is important before planning for any dental procedures to rule out the misdiagnosis and unnecessary surgical interventions.

Keywords: Labial frenum, Mixed dentition, Permanent dentition, Primary dentition, Syndromes.

The Journal of Contemporary Dental Practice (2020): 10.5005/jp-journals-10024-2794
\end{abstract}

\section{INTRODUCTION}

The labial frenum is a mucosal fold that attaches the lip to alveolar mucosa, gingiva, and periosteum" and it is defined as "a fibrous band of tissue attached to the bone of the mandible and maxillae, and it present superficial to muscle attachments." ${ }^{2}$ Histologically, it is made of loose connective tissue fibers, an abundance of elastic fibers, and mucous glands in the subcutaneous tissue on either side of the central artery and vein. ${ }^{3}$ Few striated muscle fibers also arise from the muscle bundles of the lip on either side of the midline. ${ }^{4}$

The frenum has its origin from the remnant of central cells of the vestibular lamina, and it is dynamic in its structure and often changeable in shape, size, and position during growth and development. ${ }^{5}$ It provides support and stability to the lip and to keep the lip in harmony with the growing bones of the maxilla. Hence, it plays an important role in the regulation of facial growth. ${ }^{6-8}$

The maxillary labial frenum has fibrous tissue moving in an anteroposterior direction and merges with the submucosal fibers of the upper lip. ${ }^{9}$ It also encloses the septopremaxillary ligament that serves as a means of transmitting the septal growth force to the premaxilla. It also encompasses a few striated fibers of the nasolabial muscles..$^{10}$ Inadequate muscular reconstruction and mutilation of the labial frenum could result in facial growth abnormalities. ${ }^{11}$

Aberrant frena can be detected by applying tension to see the movement of papillary tip or blanching produced on it. Clinically, papillary and papilla penetrating frena will be considered as pathological as it is associated with midline diastema, gingival recession, loss of papilla, interdental bone loss, poor lip mobility,

\footnotetext{
1,4 Department of Periodontics, SB Patil Institute of Dental Sciences and Research, Bidar, Karnataka, India

2,5 Department of Oral Medicine and Radiology, SB Patil Institute of Dental Sciences and Research, Bidar, Karnataka, India

${ }^{3}$ Department of Oral Pathology and Histology, HKES's S Nijalingappa Dental College and Hospital, Gulbarga, Karnataka, India

${ }^{6}$ Department of Prosthodontics, SB Patil Institute of Dental Sciences and Research, Bidar, Karnataka, India
}

Corresponding Author: Sharashchandra M Biradar, Department of Periodontics, SB Patil Institute of Dental Sciences and Research, Bidar, Karnataka, India, Phone: +91-9916508812, e-mail: drsharad_004p@ yahoo.co.in

How to cite this article: Biradar SM, Patil AY, Kotnoor SS, et al. Assessment of Diverse Frenal Morphology in Primary, Mixed, and Permanent Dentition: A Prevalence Study. J Contemp Dent Pract 2020;21(5):562-567.

Source of support: Nil

Conflict of interest: None

difficulty in brushing, malalignment of teeth, closure of diastema during orthodontic treatment, more retention of plaque may lead to periodontitis and reoccurrence after periodontal treatment, it may also prejudice the denture fit or retention leading to psychological disturbances to the individual. ${ }^{12,13}$

Abnormal maxillary frenal attachments may act as a hindrance for the tongue and upper lip from the seal, thus making it difficult

(c) The Author(s). 2020 Open Access This article is distributed under the terms of the Creative Commons Attribution 4.0 International License (https://creativecommons. org/licenses/by-nc/4.0/), which permits unrestricted use, distribution, and non-commercial reproduction in any medium, provided you give appropriate credit to the original author(s) and the source, provide a link to the Creative Commons license, and indicate if changes were made. The Creative Commons Public Domain Dedication waiver (http://creativecommons.org/publicdomain/zero/1.0/) applies to the data made available in this article, unless otherwise stated. 
for the children in breastfeeding which may lead to nutritional deficiency of the child. ${ }^{14}$

In the early stage of growth, the frenum is generally wide and thick, and during growth, it becomes thin and narrow. ${ }^{12,15}$ The thick labial frenum may not be able to place the bristles of brushes properly; hence, plaque control will be difficult and may lead to caries and periodontal lesions. ${ }^{16}$

There are various syndromes associated with different frenal attachments: Ehlers-Danlos syndrome, ${ }^{17}$ infantile hypertrophic pyloric stenosis, ${ }^{18}$ holoprosencephaly, ${ }^{19}$ Ellis-van Creveld syndrome, ${ }^{20}$ and orofacial-digital syndrome. ${ }^{21}$ Each syndrome exhibits relatively specific frenal abnormalities, ranging from multiple, hyperplastic, hypoplastic, or absence of frena.

The clinician may misdiagnose the frenal morphology during the early stages of growth and development; during growth, it tends to decrease in size and lose its clinical importance. During the routine clinical examination, the frenal attachment and frenal morphology may go unnoticed; however, it has been seen that abnormal frenal attachment can be an indicator of some pathology or may be associated with few syndromes.

Hence, this study aims to access the frenal morphology and frenal attachment in primary, mixed, and permanent dentition.

\section{Classification}

\section{Sewerin's Maxillary Labial Frenum Classified based on the Morphology 22}

- Simple frenum

- Persistent tectolabial frenum (PTF)

- Simple frenum with an appendix

- Simple frenum with a nodule

- Double frenum

- Frenum with a nichum

- Frenum with two or more variations at the same time.

\section{Placek's Frenum Classification based on the Attachment Site ${ }^{23}$}

- Type I-mucosal frenal attachment; the frenal fibers are attached up to the mucogingival junction.

- Type II-gingival frenal attachment; the fibers are inserted within the attached gingiva.

- Type III-papillary frenal attachment; the fibers extend into interdental papilla.

- Type IV-papillary penetrating frenal attachment; the frenal fibers cross the alveolar process and extend up to palatine papilla.

\section{Materials and Methods}

This cross-sectional study was conducted using a convenient sample size of 1,800 patients, in which 969 were male and 831 female patients aged about 3-17 years were included and equally divided into primary, mixed, and permanent dentition. The study cases were selected in the north Karnataka region irrespective of race and ethnicity. Ethical approval for the study was obtained from Al-Badar Dental College and Hospital Gulbarga. Informed consent was obtained, and the explanation of the procedure was done to parents before the examination. The study was conducted without violating the guidelines of the Declaration of Helsinki.
Three study groups were made, which includes group I: children with only primary dentition (3-6 years), group II: children with mixed dentition (7-14 years), and group III: children with complete permanent dentition (15-17 years).

Children exhibiting with congenital anomalies, systemic diseases, trauma, surgery in the maxillary anterior region, and history of previous hard and soft tissue corrective treatments were excluded from the study.

All examinations were performed by the direct visual method under the natural light by retracting the upper lip with the index finger and thumb of both hands by a single examiner. A thorough intraoral examination was carried out to assess the morphology of the maxillary labial frenum and the type of frenal attachment (Figs 1 and 2).

The types of frenal attachments were classified according to the Sewerin's ${ }^{22}$ and Placek's ${ }^{23}$ types of frenal attachment.

\section{Statistical Data Analysis}

Data collected were entered into SPSS version 16 and were subjected to statistical analysis. The genderwise distribution of frenal morphology and types of attachment were evaluated in an individual group and in between the groups.

\section{Results}

In group I (primary dentition), a total of 327 male and 273 female children were examined. Among the morphological types of frenal attachment, the most prevalent frenum type found was the simple frenum (60.2\%) followed by PTF (19.4\%) and simple with nodule (17.8\%). No significant differences between different types of frenum attachment were found in male and female children ( $p=0.97 ;$ Table $1 ; \chi^{2}=0.26, p>0.97$, not significant).

In group II (mixed dentition), a total of 319 male and 281 female children were examined. The most prevalent frenum type found was the simple type (70.2\%) followed by simple with nodule (17.9\%). No significant differences between different types of frenum attachment were found in male and female children $(p=0.97$; Table $2 ; \chi^{2}=0.854, p>0.913$, not significant).

In group III (permanent dentition), a total of 323 male and 277 female children were examined. The most prevalent frenum type found was the simple frenum (77.9\%) followed by simple frenum with appendix (14.1\%). No significant differences between different types of frenum attachment were found in male and female children ( $p=0.97$; Table $3 ; \chi^{2}=2.591, p=0.462$, not significant).

The comparison of the incidence of individual labial frenum was made between each group. It has shown a high statistically significant difference of frenal attachment within the groups (Table 4).

Based on the attachment of frenum, the comparison of the incidence of individual labial frenum was made between each group. Type III (50.7\%) frenal attachment was most prevalent followed by type II (32\%) in group I children. Type II (51.7\%) frenal attachment was most prevalent followed by type III (32.3\%) in group II children. Type II (42.3\%) frenal attachment was most prevalent followed by type III (36.5\%) in group III children. As the age advances, the frenum becomes thin and narrow and is shifted apically. There is a highly statistically significant difference of frenal attachment within the groups (Table 5; $\left.\chi^{2}=32.8, p<0.001\right)$. 


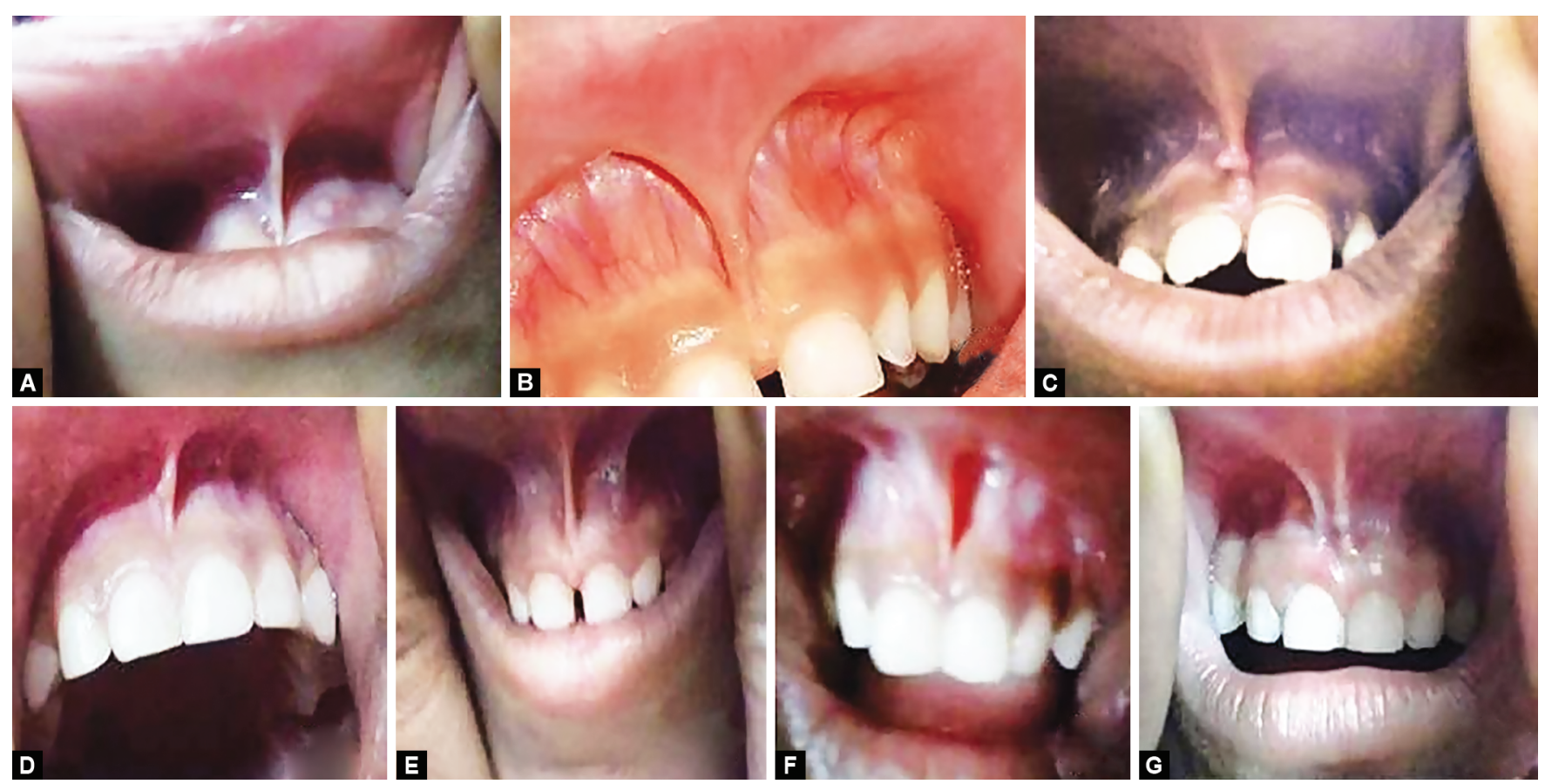

Figs 1 A to G: (A) Simple frenum; (B) Persistent tectolabial frenum; (C) Simple frenum with an appendix; (D) Simple frenum with a nodule; (E) Double frenum; (F) Frenum with a nichum; (G) Frenum with two or more variations
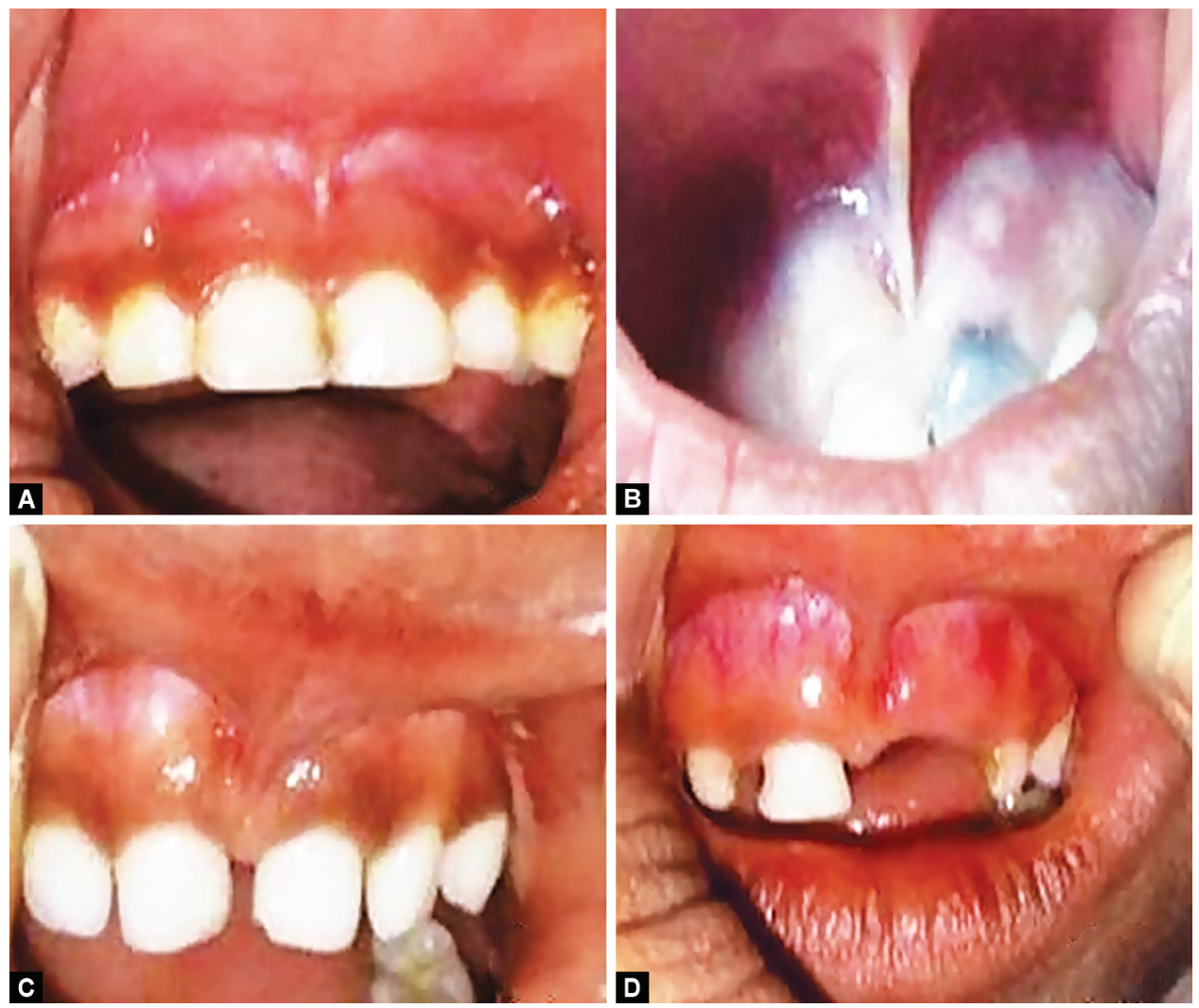

Figs 2A to D: (A) Type I frenum; (B) Type II frenum; (C) Type III frenum; (D) Type IV frenum

\section{Discussion}

The labial frenum is a mucosal fold that attaches the lip to alveolar mucosa, gingival, and periosteum. Many morphological variations and types of frenal attachment are observed in primary, mixed, and permanent dentition.
This study was conducted in 1,800 children, in which 969 male and 831 female children with age group of 3-17 years were examined, and according to the age and dentition, they are equally divided into primary, mixed, and permanent dentition. The study included all racial and ethnical group children in the 
Table 1: Incidence of labial frenum morphology by gender in group I (primary dentition)

\begin{tabular}{|c|c|c|c|c|c|c|}
\hline \multirow[b]{3}{*}{ Maxillar labial frenum type } & \multicolumn{4}{|c|}{ Gender } & & \\
\hline & \multicolumn{2}{|c|}{ Male } & \multicolumn{2}{|c|}{ Female } & \multicolumn{2}{|c|}{ Total } \\
\hline & No. & $\%$ & No. & $\%$ & No. & $\%$ \\
\hline Simple frenum & 201 & 61.5 & 160 & 58.6 & 361 & 60.2 \\
\hline PTF & 61 & 18.7 & 55 & 20.1 & 116 & 19.4 \\
\hline Simple frenum with an appendix & 3 & 0.9 & 4 & 1.5 & 7 & 1.2 \\
\hline Simple frenum with a nodule & 57 & 17.4 & 50 & 18.3 & 107 & 17.8 \\
\hline Double frenum & 2 & 0.6 & 2 & 0.75 & 4 & 0.6 \\
\hline Frenum with a nichum & 3 & 0.9 & 2 & 0.75 & 5 & 0.8 \\
\hline $\begin{array}{l}\text { Frenum with two or more variations } \\
\text { at the same time }\end{array}$ & 0 & 0.0 & 0 & 0.0 & 0 & 0.0 \\
\hline Total & 327 & 100.0 & 273 & 100.0 & 600 & 100.0 \\
\hline
\end{tabular}

Table 2: Incidence of labial frenum morphology by gender in group II (mixed dentition)

\begin{tabular}{|c|c|c|c|c|c|c|}
\hline \multirow[b]{3}{*}{ Maxillar labial frenum type } & \multicolumn{4}{|c|}{ Gender } & & \\
\hline & \multicolumn{2}{|c|}{ Male } & \multicolumn{2}{|c|}{ Female } & \multicolumn{2}{|c|}{ Total } \\
\hline & No. & $\%$ & No. & $\%$ & No. & $\%$ \\
\hline Simple frenum & 223 & 69.9 & 198 & 70.5 & 421 & 70.2 \\
\hline PTF & 26 & 8.2 & 25 & 8.9 & 51 & 8.4 \\
\hline Simple frenum with an appendix & 5 & 1.6 & 4 & 1.4 & 9 & 1.5 \\
\hline Simple frenum with a nodule & 57 & 17.9 & 50 & 17.7 & 107 & 17.9 \\
\hline Double frenum & 3 & 0.9 & 1 & 0.4 & 4 & 0.7 \\
\hline Frenum with a nichum & 3 & 0.9 & 2 & 0.7 & 5 & 0.8 \\
\hline $\begin{array}{l}\text { Frenum with two or more variations } \\
\text { at the same time }\end{array}$ & 2 & 0.6 & 1 & 0.4 & 3 & 0.5 \\
\hline Total & 319 & 100.0 & 281 & 100.0 & 600 & 100.0 \\
\hline
\end{tabular}

Table 3: Incidence of labial frenum morphology by gender in group III (permanent dentition)

\begin{tabular}{|c|c|c|c|c|c|c|}
\hline \multirow[b]{3}{*}{ Maxillar labial frenum type } & \multicolumn{4}{|c|}{ Gender } & \multirow{2}{*}{\multicolumn{2}{|c|}{ Total }} \\
\hline & \multicolumn{2}{|c|}{ Male } & \multicolumn{2}{|c|}{ Female } & & \\
\hline & No. & $\%$ & No. & $\%$ & No. & $\%$ \\
\hline Simple frenum & 252 & 78.0 & 214 & 77.3 & 466 & 77.7 \\
\hline PTF & 20 & 6.2 & 16 & 5.8 & 36 & 6.0 \\
\hline Simple frenum with an appendix & 45 & 14.0 & 40 & 14.4 & 85 & 14.1 \\
\hline Simple frenum with a nodule & 1 & 0.3 & 3 & 1.1 & 4 & 0.7 \\
\hline Double frenum & 3 & 0.9 & 2 & 0.7 & 5 & 0.8 \\
\hline Frenum with a nichum & 0 & 0.0 & 0 & 0.0 & 0 & 0.0 \\
\hline $\begin{array}{l}\text { Frenum with two or more variations } \\
\text { at the same time }\end{array}$ & 2 & 0.6 & 2 & 0.7 & 4 & 0.7 \\
\hline Total & 323 & 100.0 & 277 & 100.0 & 600 & 100.0 \\
\hline
\end{tabular}

north Karnataka region and have followed the classification according to morphological attachment, Sewerin's frenal attachment, and according to frenal attachment site, Placek's frenal attachment. $^{16,24,25}$

The most prevalent type of frenal attachment is simple frenum in all the three groups about $60.2,70$, and $77.2 \%$ in group I, group II, and group III, respectively, and these results are in accordance with Bervian et al., ${ }^{26}$ Christabel and Gurunathan, ${ }^{27}$ and Townsend et al. ${ }^{9}$

The simple frenal attachments were followed by PTF in primary dentition of $19.4 \%$, mixed dentition of $8.4 \%$, and permanent dentition of $6.0 \%$. The prevalence of simple frenum increases from primary dentition to permanent dentition, whereas PTF decreases as age increases, and these results are in accordance with Deepa, ${ }_{1}^{28}$ Lindsey, ${ }^{29}$ and Placek et al. ${ }^{30}$

The prevalence of PTF is higher in younger individuals than in adults because as age advances, there is a vertical growth of alveolar process, maxillary sinus development, and intra-alveolar eruption of the permanent maxillary incisors. This change in position during the child growth from primary to permanent dentition was believed to be caused by the frenum's static position while the surrounding structures grow. ${ }^{31}$

The simple frenum with a nodule in mixed dentition is $17.9 \%$ and in primary dentition is $17.8 \%$, and frenum with appendix is more commonly found in permanent dentition and is about $14.1 \%$; these results are in accordance with Nagveni and Umashankar. ${ }^{32}$ 
Diverse Frenal Morphology in Primary, Mixed, and Permanent Dentition

Table 4: Comparison of incidence of individual labial frenum morphology in different groups (primary dentition, mixed dentition, and permanent dentition)

\begin{tabular}{|c|c|c|c|c|c|c|c|}
\hline \multirow{2}{*}{$\begin{array}{l}\text { Maxillar labial } \\
\text { frenum type }\end{array}$} & \multicolumn{2}{|c|}{$\begin{array}{l}\text { Group I (primary } \\
\text { dentition) }\end{array}$} & \multicolumn{2}{|c|}{$\begin{array}{c}\text { Group II (mixed } \\
\text { dentition) }\end{array}$} & \multicolumn{2}{|c|}{$\begin{array}{c}\text { Group III (permanent } \\
\text { dentition) }\end{array}$} & \multirow[t]{2}{*}{$\begin{array}{l}\chi^{2} \text { test, } p \text { value and } \\
\text { significance }\end{array}$} \\
\hline & No. & $\%$ & No. & $\%$ & No. & $\%$ & \\
\hline Simple frenum & 361 & 60.2 & 421 & 70.2 & 466 & 77.7 & $\chi^{2}=56.61, p<0.001$ and VHS \\
\hline PTF & 116 & 19.4 & 51 & 8.4 & 36 & 6.0 & $\chi^{2}=82.53, p<0.001$ and VHS \\
\hline Simple frenum with an appendix & 7 & 1.2 & 9 & 1.5 & 85 & 14.1 & $\chi^{2}=241.7, p<0.001$ and VHS \\
\hline Simple frenum with a nodule & 107 & 17.8 & 107 & 17.9 & 4 & 0.7 & $\chi^{2}=123.4, p<0.001$ and VHS \\
\hline Double frenum & 4 & 0.6 & 4 & 0.7 & 5 & 0.8 & $\chi^{2}=0.34, p>0.05$ and NS \\
\hline Frenum with a nichum & 5 & 0.8 & 5 & 0.8 & 0 & 0.0 & $\chi^{2}=1.256, p>0.05$ and NS \\
\hline $\begin{array}{l}\text { Frenum with two or more variations at } \\
\text { the same time }\end{array}$ & 0 & 0.0 & 3 & 0.5 & 4 & 0.7 & $\chi^{2}=0.972, p>0.05$ and NS \\
\hline Total & 600 & 100.0 & 600 & 100.0 & 600 & 100.0 & $1,800(100.0 \%)$ \\
\hline
\end{tabular}

NS, nothing significant; VHS, very highly significant

Table 5: Comparison of incidence of individual labial frenum based on the attachment of frenum in different groups (primary dentition, mixed dentition, and permanent dentition)

\begin{tabular}{|c|c|c|c|c|c|c|}
\hline \multirow[b]{2}{*}{ Type } & \multicolumn{2}{|c|}{ Group I (primary dentition) } & \multicolumn{2}{|c|}{ Group II (mixed dentition) } & \multicolumn{2}{|c|}{ Group III (permanent dentition) } \\
\hline & No. & $\%$ & No. & $\%$ & No. & $\%$ \\
\hline 1 & 28 & 4.6 & 84 & 14 & 104 & 17.3 \\
\hline 2 & 192 & 32 & 310 & 51.7 & 254 & 42.3 \\
\hline 3 & 304 & 50.7 & 194 & 32.3 & 219 & 36.5 \\
\hline 4 & 76 & 12.7 & 12 & 2 & 23 & 3.9 \\
\hline Total & 600 & 100.0 & 600 & 100.0 & 600 & 100.0 \\
\hline
\end{tabular}

Frenum with nodule and appendix is considered as developmental remnants that show no pathological potential and do not need any investigation and treatment procedures. ${ }^{33}$ The other frenal morphologies like frenum with a nichum, double frenum, and frenum with two or more variables are found to be nil or less than $1 \%$.

There is no significant association of frenal type with gender. Both male and female children had more or less equal distribution, and these results are in accordance with Kotlow ${ }^{34}$ and Lindsey. ${ }^{29}$

Although many kinds of literature exist on the prevalence of types of frenal attachment, there was no association made with the type of dentition. ${ }^{12,33,35}$ In this study, the association was evaluated based on the attachment of frenum among the dentition. Type III (50.7\%) frenal attachment was most prevalent in group I (primary dentition) children, type II (51.7\%) in group II (mixed dentition) children, and type II (42.3\%) in group III (permanent dentition) children. In the similar studies done by Jindal et al., ${ }^{36}$ the prevalence of mucosal frenal attachment was found to be most common (66.0\%) with gingival frenal attachment as second (28.4\%) followed by papillary penetrating (3.2\%) with papillary type $(2.40 \%)$ least common, and the study done by Mirko et al., ${ }^{30}$ the prevalence was found to be as mucosal (46.6\%), gingival (34.3\%), papillary (3.1\%), and papillary penetrating (16.1\%). The difference in results in this study when compared with Jindal et al. ${ }^{36}$ and Mirko et al. ${ }^{30}$ could be due to the diversity of population and dentition.

The presence of abnormal frenum can lead to frenal pull which, in turn, leads to accumulation of plaque, gingival recession, periodontitis, interference with the retention of a denture, midline diastema formation, difficulty in the closure of diastema during orthodontic treatment, difficulty in brushing, improper pronunciation, and interference with breastfeeding by infants. ${ }^{12-16}$

The few abnormal frena may be associated with syndromes such as Ehlers-Danlos syndrome, infantile hypertrophic pyloric stenosis, holoprosencephaly, Ellis-van Creveld syndrome, and orofacial-digital syndrome. ${ }^{17-21}$ Mutations in the genes in these syndromes would prevent cells from making enough functional protein, which disrupts the normal development of frenum. ${ }^{17-21}$ A syndrome associated with abnormal frenum varies according to geographical distribution and race. The child with abnormal frenum which is associated with syndromes is not found in this region.

The study with more sample size is required to assess the frenal morphology and attachments in various race and ethnic group of children in this region, and a study with only syndromic patients with a large sample size is required to assess the detail about aberrant frena.

\section{Conclusion}

The frenum is a tiny structure but has a diverse morphology and attachment types, so it is important to access the normal and abnormal frena before planning for any dental procedures. A thorough examination of the frenum is important to rule out the misdiagnosis and unnecessary surgical interventions.

\section{References}

1. Kotlow L. Diagnosis and treatment of ankyloglossia and tied maxillary frenum in infants using Er:YAG and 1064 diode lasers. Eur Arch Paediatr Dent 2011;12(2):106-112. DOI: 10.1007/BF03262789. 
2. Zarb GA, Bryant SR. Pre-prosthetic surgery: improving the patient's denture-bearing areas and ridge relations. In: Zarb GA, Bolender $\mathrm{CL}$, ed. Prosthodontic Treatment for Edentulous Patients, Complete Dentures and Implant-Supported Prostheses. 12th ed., Amsterdam: Elsevier; 2004. p. 103.

3. Priyanka M, Sruthi R, Ramakrishnan T, et al. An overview of frenal attachments. J Indian Soc Periodontol 2013;17(1):12-15. DOI: 10.4103/0972-124X.107467.

4. Gartner LP, Schein D. The superior labial frenum: a histologic observation. Quintessence Int 1991;22(6):443-445.

5. Delli K, Livas C, Sculean A, et al. Facts and myths regarding the maxillary midline frenum and its treatment: a systematic review of the literature. Quintessence Int 2013;44(2):177-187. DOI: 10.3290/ j.qi.a28925.

6. Northcutt ME. The lingual frenum. J Clin Orthod 2009;43(9):557-565.

7. Hall BK, Precious DS. Cleft lip, nose, and palate: the nasal septum as the pacemaker for midfacial growth. Oral Surg Oral Med Oral Pathol Oral Radiol 2013;115(4):442-447. DOI: 10.1016/j.0ooo.2012. 05.005 .

8. Srinivasan B, Chittaranjan AB. Skeletal and dental characteristics in subjects with ankyloglossia. Prog Orthod 2013;14:44. DOI: 10.1186/2196-1042-14-44.

9. Townsend JA, Brannon RB, Cheramie T, et al. Prevalence and variations of the median maxillary labial frenum in children, adolescents, and adults in a diverse population. Gen Dent 2013;61(2):57-60.

10. Standerwick RG, Roberts WE. The aponeurotic tension model of craniofacial growth in man. Open Dent J 2009;3:100-113. DOI: 10.2174/1874210600903010100.

11. Delaire J. Muscle adaptation in the craniofacial region. Monograph no. 8. In: Carlson DS, McNamara JA, ed. Craniofacial Growth Series. Ann Arbor, (MI): The University of Michigan; 1978. pp. 157-180.

12. Devishree, Gujjari SK, Shubhashini PV. Frenectomy: a review with the reports of surgical techniques. J Clin Diagn Res 2012;6(9):1587-1592. DOI: $10.7860 / J C D R / 2012 / 4089.2572$.

13. Anubha N, Chaubey KK, Arora VK, et al. Frenectomy combined with a laterally displaced pedicle graft. Indian J Dent Sci 2010;2(2):47-51.

14. Wiessinger $D$, Miller M. Breastfeeding difficulties as a result of tight lingual and labial frena: a case report. J Hum Lact 1995;11(4):313-316. DOI: $10.1177 / 089033449501100419$.

15. Rajani ER, Biswas PP, Emmatty R. Prevalence of variations in morphology and attachment of maxillary labial frenum in various skeletal patterns - a cross-sectional study. J Indian Soc Periodontol 2018;22(3):257-262. DOI: 10.4103/jisp.jisp_294_17.

16. Boutsi EA, Tatakis DN. Maxillary labial frenum attachment in children. Int J Paediatr Dent 2011;21(4):284-288. DOI: 10.1111/j.1365263X.2011.01121.X.

17. De Felice $C$, Toti $P$, Di Maggio $G$, et al. Absence of the inferior labial and lingual frenula in Ehlers-Danlos syndrome. Lancet 2001;357(9267):1500-1502. DOI: 10.1016/S0140-6736(00)04661-4.

18. Jenista JA. Mandibular frenulum as a sign of infantile hypertrophic pyloric stenosis. J Pediatr 2001;138(3):447-447. DOI: 10.1067/ mpd.2001.109192.

19. Martin RA, Jones KL. Absence of the superior labial frenulum in holoprosencephaly: a new diagnostic sign. J Pediatr 1998;133(1): 151-153. DOI: 10.1016/S0022-3476(98)70198-2.
20. Babaji P. Oral abnormalities in the Ellis-van Creveld syndrome. Indian J Dent Res 2010;21(1):143-145. DOI: 10.4103/0970-9290.62791.

21. Tuli A, Sachdev V, Singh A, et al. Physical and dental manifestations of oral-facial-digital syndrome type I. J Indian Soc Pedod Prev Dent 2011;29(6 Suppl 2):S83-S86. DOI: 10.4103/0970-4388.90750.

22. Sewerin I. Prevalence of variations and anomalies of the upper labial frenum. Acta Odontol Scand 1971;29(4):487-496. DOI: 10.3109/00016357109026535.

23. Placek M, Skach M, Mrklas L. Significance of the labial frenum attachment in periodontal disease in man-part I: classification and epidemiology of the labial frenum attachment. J Periodontol 1974;45(12):891-894. DOI: 10.1902/jop.1974.45.12.891.

24. Janczuk Z, Banach J. Prevalence of a narrow zone of attached gingiva and improper attachment of labial frena in youths. Community Dent Oral Epidemiol 1980;8(7):385-386. DOI: 10.1111/j.1600-0528.1980. tb01313.x.

25. Upadhayay S, Upadaya NG. Attachment of maxillary labial frenum in Nepalese children. Orthod J Nepal 2012;2(1):28-31. DOI: 10.3126/ ojn.v2i1.9291.

26. Bervian J, Cazarotto F, Perussolo B, et al. Description of the upper labial frenulum characteristics in preschool children of Passo Fundo, Brazil. Braz Res Pediatr Dent Integr Clin 2016;16:351-357.

27. Christabel SL, Gurunathan D. Prevalence of type of frenal attachment and morphology of frenum in children, Chennai, Tamil Nadu. World J Dent 2015;6(4):203-207. DOI: 10.5005/jp-journals-10015-1343.

28. Deepa G. Attachment of maxillary frenum and occurrence of midline diastema in children. J Pharm Sci Res 2016;6(8):536-539.

29. Lindsey D. The upper mid-line space and its relation to the labial fraenum in children and in adults. A statistical evaluation. Br Dent J 1977;143(10):327-332. DOI: 10.1038/sj.bdj.4804003.

30. Mirko P, Miroslav S, Lubor M. Significance of the labial frenum attachment in periodontal disease in man. Part II. An attempt to determine the resistance of periodontium. J Periodontal 1974;45(12):895-897. DOI: 10.1902/jop.1974.45.12.895.

31. Popovich F, Thompson GW, Main PA. The maxillary interincisal diastema and its relation to the superior labial frenum and intermaxillary structure. Angle Orthod 1977;47(4):265-271. DOI: 10.1043/0003-3219(1977)047<0265:TMIDAI>2.0.CO;2.

32. Nagveni NB, Umashankar KV. Morphology of maxillary labial frenum in primary, mixed, and permanent dentition of Indian children. J Cranio Max Dis 2014;3(1):5-10. DOI: 10.4103/2278-9588. 130430.

33. Diaz-Piazen ME, Lagravere MO, Villena R. Midline diastema and frenum morphology in primary dentition. J Dent Child (Chic) 2006;73(1):11-14.

34. Kotlow LA. Oral diagnosis of abnormal frenum attachments in neonates and infants: evaluation and treatment of maxillary frenum using the erbium YAG laser. J Pediatr Dent Care 2004;10:11-14.

35. Kotlow $L A$. The influence of the maxillary frenum on the development and pattern of dental caries on anterior teeth in breastfeeding infants; prevention, diagnosis, and treatment. J Hum Lact 2001;26(3):304-308. DOI: $10.1177 / 0890334410362520$

36. Jindal V, Kaur R, Goel A, et al. Variations in the frenal morphology in the diverse population: a clinical study. J Indian Soc Periodontol 2016;20(3):320-323. DOI: 10.4103/0972-124X.182598. 